\title{
A randomized controlled trial on preweaning morbidity, growth and mortality in Holstein heifers fed a lacteal-derived colostrum replacer or pooled maternal colostrum
}

\author{
Sharif S Aly ${ }^{1,2^{*}}$, Patrick Pithua ${ }^{3}$, John D Champagne ${ }^{1}$ and Deborah M Haines ${ }^{4,5}$
}

\begin{abstract}
Background: The objective of this randomized controlled trial was to determine the effect of feeding a commercial lacteal-derived colostrum replacer (CR) or pooled maternal colostrum (MC) on preweaning morbidity, growth and mortality in Holstein heifer calves. A total of 568 calves were randomly assigned to be fed either $3.8 \mathrm{~L}$ of pooled MC or two doses (200 g lgG) of a CR. Calves were monitored daily for preweaning morbidity until weaning at $60 \mathrm{~d}$ old. Birth and weaning weights were measured to estimate growth rates.

Results: Calves fed CR were significantly less likely to be affected with a diarrhea event ( $\mathrm{OR}=0.58 ; 95 \% \mathrm{Cl}, 0.38$ to 0.88 ; $\mathrm{P}$ value $=0.011)$ and had a higher rate of daily weight gain $(0.051 \mathrm{~kg} /$ day; $95 \% \mathrm{Cl}, 0.03$ to $0.08 ; \mathrm{P}$ value $<0.001)$ compared to calves fed pooled MC. Use of lacteal-derived colostrum replacer was not significantly associated with respiratory disease $(\mathrm{OR}=1.01 ; 95 \% \mathrm{Cl} 0.67$ to 1.51 ; $\mathrm{P}$ value $=0.974)$, omphalitis $(\mathrm{OR}=0.93 ; 95 \% \mathrm{Cl} 0.06$ to 14.86 ; $\mathrm{P}$ value $=0.956)$, or mortality $(\mathrm{HR}=0.71 ; 95 \% \mathrm{Cl} 0.27$ to $1.92 ; \mathrm{P}$ value $=0.505)$ in the study calves.

Conclusions: The lacteal-derived CR fed at the study dose was a viable colostrum alternative in the event of poor quality pooled $M C$ for the prevention of preweaning diarrhea and resulted in higher growth rates in comparison to calves fed pooled MC in the study herd.
\end{abstract}

Keywords: Lacteal-derived colostrum replacer, Pooled maternal colostrum, Calf morbidity, Daily weight gain

\section{Background}

Bovine maternal colostrum (MC) contains immune factors that provide a critical first line of defense against a variety of infectious pathogens to which calves become exposed after birth [1]. There is consensus in the literature that at least $3.8 \mathrm{~L}$ of good-quality $\mathrm{MC}$ ( $\mathrm{IgG}>50 \mathrm{~g} / \mathrm{L}$ and Total Plate Counts, TPC $<100,000 \mathrm{cfu} / \mathrm{mL}$ ) should be administered to prevent failure of passive transfer (FPT) of immunity, a condition characterized by serum IgG $<10 \mathrm{~g} / \mathrm{L} \geq 24 \mathrm{~h}$ post colostrum ingestion in calves [2-4]. Failure of passive transfer of immunity is a well-

\footnotetext{
* Correspondence: saly@ucdavis.edu

'Veterinary Medicine Teaching and Research Center, School of Veterinary Medicine, University of California, Davis, 18830 Road 112, Tulare, CA 93274, USA

${ }^{2}$ Department of Population Health and Reproduction, School of Veterinary Medicine, University of California, One Shields Avenue, Davis, CA 95616, USA Full list of author information is available at the end of the article
}

recognized risk factor for increased preweaning calf morbidity and mortality [5-8]. The condition has also been associated with milk yield losses and decreased longevity in lactating adult cows $[5,6]$.

Adequate intake of $\mathrm{MC}$ is critical for preventing FPT and its negative consequences on calf health and future production performance. Several studies have confirmed the presence of bovine specific pathogens (e.g. Escherichia coli, Salmonella sp., Mycoplasma sp., bovine leukemia virus, and Mycobacterium avium subsp. paratuberculosis) in $\mathrm{MC}$ suggesting that feeding raw $\mathrm{MC}$ is an early means by which newborn calves can become exposed to such pathogens [9-15]. In addition, negative correlations have been reported between bacterial contamination levels in colostrum and post-feeding serum IgG concentrations $[3,16]$. Hence, feeding colostrum of inferior quality $(\operatorname{IgG}<$ $50 \mathrm{~g} / \mathrm{L}$ and TPC $>100,000 \mathrm{cfu} / \mathrm{mL}$ ) can exacerbate the risk 
of FPT in calves and compromise preweaning performance [3].

Colostrum replacers derived from either spray-dried bovine plasma or spray-dried cow colostrum are formulated to provide $\geq 100 \mathrm{~g}$ of IgG to calves when ingested at the replacer dose [17]. Specific heat treatment must be utilized along with spray-dry processing of the plasma or colostrum to effectively destroy all pathogens present in $\mathrm{MC}$ [18]. Therefore, CR products have the potential to limit calf exposure to bovine pathogens that may be shed or contaminate $\mathrm{MC}$ and are indicated for calves when quality or quantity (or both attributes) of raw MC may be compromised.

Previous IgG absorption studies on various CR products yielded conflicting results [19-22]. In addition, studies that report a positive association between bovine lacteal or serum based CR products and adequate transfer of immunity in calves rarely include an assessment of preweaning morbidity and performance [19-21]. In one Minnesota study, 93\% of calves fed a plasma-derived CR product (125 g of IgG) after birth experienced FPT compared with $28 \%$ of calves fed MC [19]. Even so, preweaning morbidity and mortality risks did not differ between groups in this study [22]. Several studies reported that feeding a higher IgG mass ( $\geq 200$ g of IgG) delivered using CR products resulted in greater IgG absorption and lower FPT risks [19,20,23]. However, these studies did not evaluate post-administration performance in terms of preweaning morbidity and mortality risks, feed intake, and weight gain for calves fed larger masses of IgG in the CR products evaluated.

We recently completed a study comparing IgG and serum total protein (TP) in calves fed pooled MC or lacteal-derived CR [24]. In that study, serum TP and IgG concentrations at approximately 24 hours post-colostral intake were significantly lower for calves fed pooled $\mathrm{MC}$ $(\mathrm{TP}=4.77 \mathrm{~g} / \mathrm{dL}, \quad \mathrm{SD}=0.55 ; \quad \operatorname{IgG}=7.50 \mathrm{~g} / \mathrm{L}, \quad \mathrm{SD}=5.0)$ compared to calves fed CR $(\mathrm{TP}=5.50 \mathrm{~g} / \mathrm{dL}, \mathrm{SD}=0.52$; $\operatorname{IgG}=15.15 \mathrm{~g} / \mathrm{L}, \mathrm{SD}=4.75)$. Colostrum IgG concentration and mass fed were significantly higher in the CR (71.4 g/L; 200 g, respectively) compared with MC group (21.08 g/L, SD = 9.77; 79.79 g, SD = 36.96, respectively). The apparent efficiency of IgG absorption (AEA) was similar for calves fed MC $(28.79 \%, \mathrm{SD}=2.098)$ or $\mathrm{CR}$ $(26.98 \%, \mathrm{SD}=1.65)$. A significantly higher proportion of calves fed MC (188/269 [70\%]) suffered from FPT (serum IgG $<10 \mathrm{~g} / \mathrm{L}$ ) compared with calves fed CR (32/ $292[11 \%])(P<0.001)$. However, producers are often interested not only in passive transfer of immunity in calves, but also in preweaning health and growth rates. The objective of this randomized trial was to determine the effect of feeding a higher dose of a commercial lacteal-derived $\mathrm{CR}$ or pooled $\mathrm{MC}$ on preweaning morbidity, daily weight gain and mortality in Holstein heifer calves.

\section{Results}

\section{Descriptive data}

In total, 568 newborn calves were enrolled in the study. Of these, 273 (48\%) were fed pooled MC while 295 (52\%) were fed lacteal derived-CR. Calves did not significantly differ in birth weight, precolostral serum IgG or total protein between trial groups $(P$ value $>0.05)$. In addition, calves fed $\mathrm{MC}$ or $\mathrm{CR}$ did not differ in time to separation from dam $(2.35$ hours $(\mathrm{SD}=2.42)$ and 2.34 $(\mathrm{SD}=2.42)$, respectively) and time to feeding colostrum (3.99 hours $(\mathrm{SD}=2.31)$ and 4.12 hours $(\mathrm{SD}=2.25)$, respectively).

Preweaning health and mortality events and the mean birth and weaning weights are summarized in Table 1. The proportion of calves with diarrhea, and those treated with antibiotics were significantly higher for calves fed pooled MC compared with calves fed lactealderived CR. However, the proportions of calves with respiratory disease, omphalitis or those that died in the preweaning period were similar between groups (CR vs. pooled MC, Table 1 ). The preweaning mean daily weight gain was significantly higher $(\mathrm{P}<0.0001$, Table 1$)$ in calves fed lacteal-derived CR compared with calves fed pooled MC.

\section{Multivariable models}

Heifer calves fed lacteal-derived CR were significantly less likely to experience a preweaning event of diarrhea $(O R=$ $0.58 ; 95 \% \mathrm{CI}=0.38$ to 0.88 ) (Table 2 ). Similarly, calves fed lacteal-derived $\mathrm{CR}$ were less likely to be treated with antibiotics during the preweaning period $(O R=0.66$; $95 \% \mathrm{CI}=$ 0.47 to 0.93 ), compared with calves fed pooled MC. While calves fed $200 \mathrm{~g}$ IgG in lacteal-derived CR (vs. pooled MC) at birth experienced significantly higher preweaning mean daily weight gain by $0.051 \mathrm{~kg} / \mathrm{d}(95 \% \mathrm{CI}=0.026$ to 0.075 ; $P$ value $<0.001)$, the risk of respiratory disease and omphalitis was not dependent on the type of colostrum fed (Table 2). In addition, the Hazard Rate Ratio (HRR) estimated from the Cox proportional hazard model showed that there was no significant effect of type of colostrum fed on the hazard for mortality $(\mathrm{HRR}=0.71 ; 95 \% \mathrm{CI}=0.27$ to $1.92 ; \mathrm{P}=0.505$ ).

Based on findings from this study, we estimate that routine feeding of $200 \mathrm{~g}$ of IgG (formulated as the current lacteal-derived CR powder) instead of pooledMC could eliminate approximately one-fifth of the cases of diarrhea (Population Attributable Fraction, PAF = 0.21 ; $95 \% \mathrm{CI}=0.03$ to 0.35 ) and approximately onetenth of the number of antibiotic-treated calves (PAF = 0.12 ; $95 \%$ CI 0.02 to 0.22 ) in this population (Table 3 ).

\section{Discussion}

As reported elsewhere [24], a significantly higher proportion of calves fed pooled-MC (70\%) suffered from 
Table 1 Comparison of preweaning morbidity, growth and mortality in a randomized trial of the effect of feeding a lacteal-derived colostrum replacer (CR) or pooled maternal colostrum (MC) in calves

\begin{tabular}{|c|c|c|c|c|c|c|c|c|c|}
\hline & \multicolumn{8}{|c|}{ Treatment group } & \multirow[t]{4}{*}{$P$ value } \\
\hline & \multicolumn{4}{|c|}{ Lacteal-derived CR } & \multicolumn{4}{|c|}{ Pooled MC } & \\
\hline & \multirow[t]{2}{*}{ Estimate } & \multirow[t]{2}{*}{$\mathbf{n}$} & \multicolumn{2}{|c|}{$\begin{array}{c}95 \% \text { Confidence } \\
\text { interval }\end{array}$} & \multirow[t]{2}{*}{ Estimate } & \multirow[t]{2}{*}{$\mathbf{n}$} & \multicolumn{2}{|c|}{$\begin{array}{c}95 \% \text { Confidence } \\
\text { interval }\end{array}$} & \\
\hline & & & Lower & Upper & & & Lower & Upper & \\
\hline Number of calves enrolled & & 295 & & & & 273 & & & \\
\hline \multicolumn{10}{|l|}{ Preweaning health events } \\
\hline Diarrhea (\%) & 15.9 & 47 & 11.8 & 20.1 & 24.5 & 67 & 19.4 & 29.6 & 0.011 \\
\hline Respiratory disease (\%) & 21.4 & 63 & 16.7 & 26.0 & 21.2 & 58 & 16.4 & 26.1 & 0.974 \\
\hline Omphalitis (\%) & 0.3 & 1 & 0.0 & 1.0 & 0.4 & 1 & 0.0 & 1.1 & 0.956 \\
\hline Treatment with antibiotics (\%) & 33.6 & 99 & 28.2 & 38.9 & 43.2 & 118 & 37.3 & 49.1 & 0.018 \\
\hline No health events or treatments (\%) & 63.4 & 187 & 57.9 & 68.9 & 54.2 & 148 & 48.3 & 60.1 & 0.026 \\
\hline Preweaning mortality/100 calves, 60 -day follow-up period & 2.4 & 7 & 0.6 & 4.1 & 3.3 & 9 & 1.2 & 5.4 & 0.506 \\
\hline Mean birth weight $(\mathrm{kg})$ & 39.1 & 293 & 38.5 & 39.7 & 39.4 & 269 & 38.8 & 40.1 & 0.452 \\
\hline Weaning weight (kg) & 58.9 & 275 & 57.9 & 59.8 & 57.0 & 248 & 56.0 & 57.9 & 0.006 \\
\hline Mean daily weight gain (kg/day) & 0.405 & 274 & 0.388 & 0.422 & 0.355 & 247 & 0.337 & 0.372 & $<0.001$ \\
\hline
\end{tabular}

FPT (serum IgG $<10 \mathrm{~g} / \mathrm{L}$ ) in comparison to calves fed lacteal-derived CR (11\%). Failure of passive transfer of immunity is a well-recognized predictor for increased preweaning calf morbidity [5-8]. It is therefore not surprising that calves fed raw pooled $\mathrm{MC}$ in this study were more likely to be treated with antibiotics or experience preweaning event of diarrhea compared with calves fed lacteal-derived CR in the study herd.

Bovine specific pathogens (Salmonella sp., Escherichia coli, Mycoplasma sp.) are frequently shed in colostrum of infected fresh cows either during an epidemic or intermittently during the peripartum period [3]. It is possible that the higher proportion of diarrhea in preweaned calves fed pooled MC (vs. lacteal-derived CR) was a consequence of direct ingestion of such pathogens in pooled MC. However, this theory could not be further investigated given that culture of the pooled MC samples for specific pathogens (example Salmonella sp., Escherichia coli, Mycoplasma sp.) was not performed in the current study.

Our results indicate that only $21 \%$ of diarrhea cases and $12 \%$ of antibiotic-treated calves would be eliminated in this population if the pooled $\mathrm{MC}$ feeding program was replaced by $200 \mathrm{~g}$ IgG/ calf delivered in a lactealderived CR product. This should not be surprising given that in replacement heifer rearing, improved preweaning health is a function of several factors including reducing calf exposure to risk factors (infectious agents inclusive).

Table 2 Final model estimates for preweaning morbidity and mortality events in a randomized trial of the effect of feeding a lacteal-derived colostrum replacer (CR) compared to pooled maternal colostrum (MC) in calves

\begin{tabular}{|c|c|c|c|c|c|c|}
\hline \multirow[t]{2}{*}{ Outcome } & \multirow{2}{*}{$\begin{array}{l}\text { Type of } \\
\text { colostrum }\end{array}$} & \multicolumn{2}{|c|}{ Number of calves } & \multirow[t]{2}{*}{$\beta$ coefficient (SE) } & \multirow[t]{2}{*}{$P$ value } & \multirow[t]{2}{*}{$\mathrm{OR}^{*}(95 \% \mathrm{Cl})$} \\
\hline & & At risk & Events & & & \\
\hline \multirow[t]{2}{*}{ Diarrhea } & Lacteal-derived CR & 295 & 47 & $-0.540(0.212)$ & 0.011 & 0.58 (0.38 to 0.88$)$ \\
\hline & Pooled MC & 273 & 67 & Reference & - & \\
\hline \multirow[t]{2}{*}{ Respiratory disease } & Lacteal-derived CR & 295 & 63 & $0.007(0.205)$ & 0.974 & $1.01(0.67$ to 1.51$)$ \\
\hline & Pooled MC & 273 & 58 & Reference & - & \\
\hline \multirow[t]{2}{*}{ Omphalitis } & Lacteal-derived CR & 295 & 1 & $-0.078(1.417)$ & 0.956 & $0.93(0.06$ to 14.86$)$ \\
\hline & Pooled MC & 273 & 1 & Reference & - & \\
\hline \multirow[t]{2}{*}{ Treatment with antibiotics } & Lacteal-derived CR & 295 & 99 & $-0.410(0.174)$ & 0.018 & 0.66 (0.47 to 0.93$)$ \\
\hline & Pooled MC & 273 & 118 & Reference & - & \\
\hline \multirow[t]{2}{*}{ Healthy calves** } & Lacteal-derived CR & 295 & 187 & $0.380(0.171)$ & 0.027 & 1.46 (1.05 to 2.05$)$ \\
\hline & Pooled MC & 273 & 148 & Reference & - & \\
\hline
\end{tabular}

* OR is the ratio of the odds of outcome in calves fed lacteal-derived CR to the odds of outcome in calves fed pooled maternal colostrum

** Calves raised from birth to weaning without morbidity or treatment with antibiotics. 


\begin{tabular}{|c|c|c|c|}
\hline \multirow[b]{2}{*}{ Item } & \multicolumn{2}{|c|}{ PAF } & \multirow[b]{2}{*}{$P$ value } \\
\hline & Estimate (\%) & $\begin{array}{c}\text { 95\% Confidence } \\
\text { interval }\end{array}$ & \\
\hline Diarrhea & 21 & 3.3 to 35 & 0.021 \\
\hline $\begin{array}{l}\text { Treated with } \\
\text { antibiotics }\end{array}$ & 12 & 1.5 to 22 & 0.026 \\
\hline
\end{tabular}

This can be accomplished through proper housing, ventilation, and general hygiene; increasing levels of specific and non-specific immunity through providing good quality colostrum, balanced nutrition, stress minimization; and boosting specific resistance through preventive vaccinations of either the dams or newborn calves against specific pathogens $[22,25,26]$. Calves in the present study were housed in raised individual wooden hutches up to $60 \mathrm{~d}$ of age and maintained on preweaning diets of milk replacer, calf starter grain, and fresh water ad libitum. While a number of calf management practices were in place to reduce calf exposure to risk factors for disease in the current herd, it is possible that some yet unidentified factor (unrelated to pooled MC) may have contributed to the additional risk of diarrhea (e.g. compromised sanitation) leading to increased antimicrobial use on this specific farm.

The overall finding that calves fed raw pooled MC (vs. lacteal-derived $\mathrm{CR}$ ) were more likely to be treated with antibiotics or experience preweaning diarrhea differed from a previous report [22]. Swan et al. reported no difference in post-feeding morbidity risk observed between calves fed a plasma-derived CR compared with calves fed individual maternal colostrum (i.e. non-pooled colostrum) [22]. In contrast, another study found significantly lower morbidity risk for calves fed MC (46.9\%) compared with calves fed a lacteal-derived CR (67.3\%) [27]. Although not statistically significant, Priestley et al. reported that a greater proportion of calves fed a lactealderived CR experienced diarrhea (44.9\%) compared to calves fed MC (28.6\%) [27,28]. Although some studies have found no link between FPT and the risk of treatment for diarrhea in beef calves, a possible reason for the difference in findings could be the higher proportion of FPT in calves fed MC in the current study, and in calves fed a lacteal-derived CR (vs. MC) in the Priestley et al. study [27-29]. The difference in FPT is likely to be due to better quality MC fed to calves in the aforementioned studies compared to the current study [22,27]. In a recent survey, $41 \%$ of individual colostrum samples met industry recommended colostrum quality benchmarks
(IgG $>50 \mathrm{~g} / \mathrm{L}$ and TPC $<100,000 \mathrm{cfu} / \mathrm{mL}$ ) compared with only $26 \%$ of pooled colostrum samples [30,31]. The mean IgG mass in the pooled MC fed to the calves in this study was approximately $21 \mathrm{~g} / \mathrm{L}$ compared with approximately $69.7 \mathrm{~g} / \mathrm{L}$ of IgG reported for non-pooled colostrum in the recent survey of colostrum quality $[24,30]$.

While there were no differences in the proportion of preweaning respiratory disease, omphalitis or death in calves fed lacteal-derived CR compared to those fed pooled $\mathrm{MC}$, mean daily weight gain was significantly higher in the former. This reflected perhaps a general benefit accruing from the improved preweaning health outcomes associated with feeding lacteal-derived CR rather than a direct role in enhancing daily weight gain in the study calves [2]. Such a link between reduced morbidity and increased weight gain was also reported in a Florida study, although unlike in the current study, the Florida study reported reduced morbidity in calves fed MC compared to those fed a lacteal-derived CR $[27,28]$.

In the current study, type of colostrum fed (CR versus $\mathrm{MC}$ ) had no effect on mortality risk between birth and weaning in the study calves. These results are consistent with results from an earlier study in which feeding a plasma-derived CR (vs MC) had no effect on preweaning mortality [22]; however they differed from the Florida study which found a significantly lower proportion of mortality in calves fed MC compared to calves fed a lacteal-derived CR [27]. These contradictions may reflect the fact that in concert with passive transfer of immunity, calf survival in the preweaning period is a function of several herd factors including housing and nutrition.

Although a major strength of this study included its randomized assignment of treatment, the results presented here must be interpreted cautiously. It is possible that the ability to correctly assign a disease diagnosis (i.e. diarrhea, respiratory disease, omphalitis) varied among the study personnel involved in the care of the calves during the follow-up period. This potential bias, if present, was likely to be non-differential because the study personnel were blinded to treatment group assignment (lacteal-derived CR vs. pooled MC). Moreover, a veterinarian (SA) crossvalidated each recorded diagnosis and treatment with the herd veterinarian's drug protocols. The extent to which this study's results can be extrapolated to a wider population of dairy herds is limited by the use of a single herd to evaluate the current study objectives. While approximately $57 \%$ of large dairy operations in the US routinely feed pooled MC [31], the current herd was not representative of this wider population with respect to FPT risk profiles and quality of pooled MC fed. Recent findings [32] suggest that approximately $23 \%$ of calves in US operations that fed pooled MC experienced FPT compared with $70 \%$ of calves fed the pooled $\mathrm{MC}$ in this study. In addition, the mean IgG mass in the pooled MC fed to the calves in this study 
was 3-fold lower than similar estimates of IgG concentration in nationally representative samples of pooled MC [30]. The lower quality of the pooled MC fed to calves in this study compared to comparable US herds likely biased the morbidity outcomes in a direction suggestive of a better efficacy for the lacteal-derived-CR for improving preweaning health in calves. Hence, it is possible that the benefits of feeding lacteal-derived CR (vs. pooled $\mathrm{MC}$ ) on preweaning health may not be similar in dairy herds managed under a different husbandry system.

The findings reported here indicate that producers should adopt colostrum management strategies that improve colostrum quality. To achieve this, producers can begin by pooling only colostrum with acceptable immunoglobulin concentration $(>50 \mathrm{~g} / \mathrm{liter} \mathrm{IgG})$. This can be achieved by testing individual cow colostrum samples prior to pooling and by properly identifying dams so that first milking colostrum is pooled separate from colostrum harvested from subsequent milkings. Alternatively, pooling colostrum can be replaced by feeding a colostrum replacement product with a known immunoglobulin concentration. Other recommendations identified from previous research should also be followed such as observing proper sanitation and hygiene during harvesting, processing, and storage of colostrum, feeding colostrum replacement products or heat-treated colostrum $[2,3,33]$.

\section{Conclusions}

In this study, calves fed CR had a significantly higher rate of daily weight gain and were less likely to be affected with diarrhea compared to calves fed MC. Type of colostrum fed was not predictive of the preweaning risks for pneumonia and mortality in this particular herd. Although a major strength of this study included its randomized design, the extent to which the current findings can be extrapolated to a wider population of dairy herds may be limited by the use of a single herd.

\section{Methods}

This study was approved by the Institutional Animal Use and Care Committee at the University of California, Davis and the University of Missouri -Columbia (Protocol \# 6439).

\section{Herd selection criteria}

This study was conducted in a 3,600 milking Holstein dairy in California that routinely fed $3.8 \mathrm{~L}$ of raw pooled $\mathrm{MC}$ to newborn calves. The study herd was selected based on its large size, maintenance of electronic records through participation in the California Dairy Herd Information Association routine milk testing and willingness of the owner to comply with the study requirements. Monthly bulk tank milk cultures conducted over the
12 months prior to the study were negative for Mycoplasma species by culture on Hayflick medium and enrichment broth.

\section{Feeding protocols and experimental design}

A total of 568 newborn calves were enrolled in the study between September and December, 2010 while the follow up period ended in March 2011. Pregnant dams were moved to a group calving pen approximately $3 \mathrm{~d}$ prior to the expected calving date and monitored until calving. Heifer calves born between $6 \mathrm{AM}$ and midnight were separated from their dams immediately after birth. Cows calving otherwise were monitored by the dairy's night shift staff and newborn calves were removed immediately after birth to the holding pen until fed the assigned colostrum type by study personnel the following morning. Once in the holding pen, each calf had its navel dipped in an iodine-based antibacterial solution, its ear tagged and its dam ID recorded on farm paper records.

Calves were randomized to one of two treatment groups and fed either $3.8 \mathrm{~L}$ of raw pooled MC (control group, $\mathrm{n}=273$ ) or two doses of a lacteal-derived $\mathrm{CR}$ (Land O Lakes Colostrum Replacement, Lake O Lakes Animal Milk Products) (treatment group, $\mathrm{n}=295$ ). The CR was reconstituted based on the manufacturer's instructions as follows. Each package (100 g IgG/dose) of the lacteal-derived $\mathrm{CR}$ powder was dissolved in $1 \mathrm{~L}$ of warm water (approx. $49^{\circ} \mathrm{C}$ ) yielding a mixture of $1.4 \mathrm{~L}$ containing $71.4 \mathrm{~g} / \mathrm{L}$ of IgG. Maternal colostrum was harvested after morning milking sessions within 1 to $12 \mathrm{~h}$ of calving, pooled and refrigerated at $4^{\circ} \mathrm{C}$ until feeding within $6-12 \mathrm{~h}$ of collection. Both the lacteal-derived $\mathrm{CR}$ and pooled $\mathrm{MC}$ were administered as a single oral dose (CR $\sim 2.8 \mathrm{~L}$ and $\mathrm{MC} \sim 3.8 \mathrm{~L}$ ) within $6 \mathrm{~h}$ of birth. All calves were fed using a bottle nipple. However, when a calf failed to ingest some or all of the colostrum quantity, an esophageal tube feeder was used to deliver the complete dose in lieu of the bottle.

Following feeding, each calf was housed in an individual raised wooden hutch until weaning at approximately $60 \mathrm{~d}$ of age. During the preweaning period, calves were fed daily diets consisting of $2 \mathrm{~L}$ of pasteurized hospital pen milk, clean water and a starter grain mix.

\section{Enrollment and preweaning health monitoring}

Before feeding the assigned colostrum type, calves were bled for serum IgG and TP concentration estimation. Calves were also weighed $(\mathrm{kg})$ at birth and weaning which occurred at approximately 60 days of age. Other data recorded included dam identification, colostrum type fed (lacteal-derived CR or pooled MC), birth date, time from birth to separation from dam (h), time from birth to colostrum feeding (h), quantity of colostrum fed 
(L) and whether or not an esophageal tube feeder was used to administer the colostrum.

Calf morbidity from birth to weaning were monitored and recorded daily by trained study personnel including study authors (SA and JC) while blinded to the type of colostrum fed (lacteal-derived CR or pooled MC) at enrollment. For uniformity in morbidity recordings the following working definitions were applied based on a modification of the University of Wisconsin Calf Health Scoring Chart (http://www.vetmed.wisc.edu/dms/fapm/ fapmtools/8calf/calf_health_scoring_chart.pdf): (I) diarrhea was indicated in calves that voided abnormal feces with watery consistency and foul smell (score 2 or 3 ) with or without dehydration or elevated body temperature $\left(\geq 40^{\circ} \mathrm{C}\right)$, (II) respiratory disease was reported for calves that exhibited increased respiratory rate, nasal discharges, or cough (score 1, 2 or 3 except no attempt was made to induce a cough) with or without an elevated body temperature $\left(\geq 40^{\circ} \mathrm{C}\right.$ ), (III) omphalitis (navel infections) was associated with presence of overt umbilical inflammatory signs, including heat, swelling, purulent discharges, or evidence of pain on palpation of the umbilical area. Furthermore, a calf's joints were physically examined for heat if a joint or umbilicus appeared enlarged. Treatments including antibiotics administered by the dairy's staff to the study calves were recorded on a daily basis. No specific treatment protocols were developed for this study. Instead, dairy staff relied on protocols implemented by the herd veterinarian. All morbidity events and treatments recorded were validated by a veterinarian (SA).

\section{Statistical analysis}

An estimate for daily weight gain (DWG) for each calf was calculated using the following formula: DWG = (WWT-BWT)/ T; where DWG = Daily weight gain $(\mathrm{kg})$, WWT = weaning weight $(\mathrm{kg}), \mathrm{BWT}=$ birth weight $(\mathrm{kg})$, $\mathrm{T}=$ age of the calf at weaning (d). Mean \pm standard error of the mean (SEM) for birth weights, weaning weights, and daily weight gains were calculated. The proportion of calves with an event of diarrhea, respiratory disease, omphalitis, and treated with antibiotics during the preweaning period were calculated for each group (lacteal-derived CR vs. pooled MC). Similarly, the proportion of healthy calves defined as the proportion of calves that did not experience a morbidity event and were not treated with antibiotics from birth to weaning was compared between the study groups. The distribution of the preceding variables between groups (lacteal-derived CR vs. pooled $\mathrm{MC}$ ) was tested using $t$-tests for continuous variables (birth weight, weaning weights and daily weight gain) and Pearson $\chi^{2}$-test for categorical variables (diarrhea, respiratory disease, omphalitis, and preweaning treatments with antibiotics, healthy calves, and death).
The association between type of colostrum fed (lacteal-derived CR vs. pooled MC) and diarrhea, respiratory disease, omphalitis, treatment with antibiotics, or producing a healthy calf from birth to weaning were investigated by fitting 5 separate logistic regression models to the data for each outcome. Birth weight and the method by which colostrum was fed (tube vs. bottle feeding) were presented to each model as additional independent variables in a manual forward stepwise selection procedure. Variables that significantly improved model fit based on the Akaike Information Criterion (AIC) values and likelihood ratio test $P<0.05$ were retained or else excluded from the final models. Population attribution fractions for lacteal-derived CR as a predictor of diarrhea, and treatment with antibiotics in the study calves were estimated separately. Population attributable fractions were estimated using the approach of Greenland and Drescher [34].

Next, to quantify the effect of feeding a lacteal-derived $\mathrm{CR}$ (vs. pooled MC) on preweaning time (d) to death, a Cox proportional hazards regression model was fitted to the preweaning mortality data to compare the hazard rate (HR) for mortality in calves fed CR to the HR in calves fed MC using the HRR [35]. Graphical evaluation of the Cox proportional hazard assumption for the treatment group (pooled MC vs. lacteal-derived $\mathrm{CR}$ ) variable revealed no evidence of violation of the proportional hazards assumption [36].

Finally, a simple least-squares regression model was fitted to the data to evaluate the effect of treatment (lacteal-derived CR (vs. pooled MC) on daily weight gain. Data was analyzed using standard software (Stata ${ }^{\circ}$ Corp., College Station, TX, USA). A 5\% level of significance was indicative of statistical significance.

\section{Competing interest}

Dr. Haines is affiliated with The Saskatoon Colostrum Co. Ltd., the manufacturer of the product kindly donated for the purpose of this study. Her participation did not influence or bias the performance or presentation of the research described in this manuscript in any way.

\section{Authors' contributions}

SSA, conducted the study, supervised the experiments, performed statistical analysis, and wrote the manuscript. PP conceived the study design, obtained funding for the study, and was actively involved in interpreting the data and writing the manuscript. JDC was actively involved in assisting with supervision of the experiment and data collection. DMH assisted with data interpretation. All authors reviewed and approved the final manuscript.

\section{Acknowledgements}

This study was supported in part by School of Veterinary Medicine, University of California, Davis faculty research funds and the USDA-Animal Health Formula Funds administered by the Committee on Research Grant at the College of Veterinary Medicine, University of Missouri-Columbia. The lacteal-derived CR product was a generous donation of the Saskatoon Colostrum Company, Saskatoon, Canada. The authors thank the study dairy owner, manager and staff for their cooperation. 


\section{Author details}

${ }^{1}$ Veterinary Medicine Teaching and Research Center, School of Veterinary Medicine, University of California, Davis, 18830 Road 112, Tulare, CA 93274 USA. ${ }^{2}$ Department of Population Health and Reproduction, School of Veterinary Medicine, University of California, One Shields Avenue, Davis, CA 95616, USA. ${ }^{3}$ Department of Veterinary Medicine \& Surgery, Veterinary Medicine Teaching Hospital, College of Veterinary Medicine, University of Missouri, 900 E. Campus Drive, Columbia MO 65211, USA. ${ }^{4}$ Department of Veterinary Microbiology, Western College of Veterinary Medicine, University of Saskatchewan, Saskatoon S7N 5A2SK, Canada. ${ }^{5}$ The Saskatoon Colostrum Co. Ltd, 30 Molaro Place, Saskatoon S7K 6A2SK, Canada.

Received: 13 December 2012 Accepted: 15 August 2013 Published: 21 August 2013

\section{References}

1. Davis $\mathrm{CL}$, Drackley JK: The development, nutrition, and management of the young calf. Ames, lowa: lowa State University Press; 1998.

2. Godden SM: Colostrum management for dairy calves. Vet Clin North Am Food Anim Pract 2008, 24:19-39.

3. Godden SM, Smolenski DJ, Donahue M, Oakes JM, Bey R, Wells S, Sreevatsan S, Stabel J, Fetrow J: Heat-treated colostrum and reduced morbidity in preweaned dairy calves: results of a randomized trial and examination of mechanisms of effectiveness. J Dairy Sci 2012, 95:4029-4040.

4. McGuirk SM, Collins M: Managing the production, storage, and delivery of colostrum. Vet Clin North Am Food Anim Pract 2004, 20:593-603.

5. DeNise SK, Robison JD, Stott GH, Armstrong DV: Effects of passive immunity on subsequent production in dairy heifers. J Dairy Sci 1989, 72:552-554.

6. Donovan GA, Dohoo IR, Montgomery DM, Bennett FL: Associations between passive immunity and morbidity and mortality in dairy heifers in Florida, USA. Prev Vet Med 1998, 34:31-46.

7. Robison JD, Stott GH, DeNise SK: Effects of passive immunity on growth and survival in the dairy heifer. J Dairy Sci 1988, 71:1283-1287.

8. Virtala AM, Grohn YT, Mechor GD, Erb HN: The effect of maternally derived immunoglobulin $\mathrm{G}$ on the risk of respiratory disease in heifers during the first 3 months of life. Prev Vet Med 1999, 39:25-37.

9. Nagy DW, Tyler JW, Kleiboeker SB: Timing of seroconversion and acquisition of positive polymerase chain reaction assay results in calves experimentally infected with bovine leukemia virus. Am J Vet Res 2007 68:72-75.

10. Nielsen SS, Bjerre H, Toft N: Colostrum and milk as risk factors for infection with mycobacterium avium subspecies paratuberculosis in dairy cattle. J Dairy Sci 2008, 91:4610-4615.

11. Pithua P, Godden SM, Wells SJ, Oakes MJ: Efficacy of feeding plasmaderived commercial colostrum replacer for the prevention of transmission of Mycobacterium avium subsp paratuberculosis in Holstein calves. J Am Vet Med Assoc 2009, 234:1167-1176.

12. Steele ML, McNab WB, Poppe C, Griffiths MW, Chen S, Degrandis SA, Fruhner LC, Larkin CA, Lynch JA, Odumeru JA: Survey of ontario bulk tank Raw milk for food-borne pathogens. J Food Prot 1997, 60:1341-1346.

13. Streeter RN, Hoffsis GF, Bech-Nielsen S, Shulaw WP, Rings DM: Isolation of Mycobacterium paratuberculosis from colostrum and milk of subclinically infected cows. Am J Vet Res 1995, 56:1322-1324.

14. Sweeney RW, Whitlock RH, Rosenberger AE: Mycobacterium paratuberculosis cultured from milk and supramammary lymph nodes of infected asymptomatic cows. J Clin Microbiol 1992, 30:166-171.

15. Walz PH, Mullaney TP, Render JA, Walker RD, Mosser T, Baker JC: Otitis media in preweaned Holstein dairy calves in Michigan due to Mycoplasma bovis. J Vet Diagn Invest 1997, 9:250-254

16. Johnson JL, Godden SM, Molitor T, Ames T, Hagman D: Effects of feeding heat-treated colostrum on passive transfer of immune and nutritional parameters in neonatal dairy calves. J Dairy Sci 2007, 90:5189-5198.

17. Quigley JD, Strohbehn RE, Kost CJ, O'Brien MM: Formulation of colostrum supplements, colostrum replacers and acquisition of passive immunity in neonatal calves. J Dairy Sci 2001, 84:2059-2065.

18. Chelack BJ, Morley PS, Haines DM: Evaluation of methods for dehydration of bovine colostrum for total replacement of normal colostrum in calves. Can Vet J 1993, 34:407-412.
19. Fidler AP, Alley ML, Smith GW: Short communication: serum immunoglobulin $\mathrm{G}$ and total protein concentrations in dairy calves fed a colostrum-replacement product. J Dairy Sci 2011, 94:3609-3612.

20. Foster DM, Smith GW, Sanner TR, Busso GV: Serum IgG and total protein concentrations in dairy calves fed two colostrum replacement products. J Am Vet Med Assoc 2006, 229:1282-1285.

21. Godden SM, Haines DM, Hagman D: Improving passive transfer of immunoglobulins in calves. I: dose effect of feeding a commercial colostrum replacer. J Dairy Sci 2009, 92:1750-1757.

22. Swan H, Godden S, Bey R, Wells S, Fetrow J, Chester-Jones H: Passive Transfer of Immunoglobulin G and Preweaning Health in Holstein Calves Fed a Commercial Colostrum Replacer. J Dairy Sci 2007, 90:3857-3866.

23. Poulsen KP, Foley AL, Collins MT, McGuirk SM: Comparison of passive transfer of immunity in neonatal dairy calves fed colostrum or bovine serum-based colostrum replacement and colostrum supplement products. J Am Vet Med Assoc 2010, 237:949-954.

24. Pithua P, Aly SS, Haines DM, Champagne JD, Middleton JR, Poock SE: Efficacy of feeding a lacteal-derived colostrum replacer or pooled maternal colostrum with a low lgG concentration for prevention of failure of passive transfer in dairy calves. J Am Vet Med Assoc 2013, 243:277-282.

25. Davis R, Giquere $\mathrm{S}$ : Evaluation of five commercially available assays and measurement of serum total protein concentration via refractometry for the diagnosis of failure of passive transfer of immunity in foals. J Am Vet Med Assoc 2005, 227:1640-1645.

26. Pithua P, Wells SJ, Godden SM, Raizman EA: Clinical trial on type of calving pen and the risk of disease in Holstein calves during the first $90 \mathrm{~d}$ of life. Prev Vet Med 2009, 89:8-15.

27. Priestley D, Bittar JH, Ibarbia L, Risco CA, Galvao KN: Effect of feeding maternal colostrum or plasma-derived or colostrum-derived colostrum replacer on passive transfer of immunity, health, and performance of preweaning heifer calves. J Dairy Sci 2013, 96:3247-3256.

28. Waldner $\mathrm{CL}$, Rosengren LB: Factors associated with serum immunoglobulin levels in beef calves from Alberta and Saskatchewan and association between passive transfer and health outcomes. Can Vet J 2009, 50:275-281.

29. Filteau V, Bouchard E, Fecteau G, Dutil L, DuTremblay D: Health status and risk factors associated with failure of passive transfer of immunity in newborn beef calves in Quebec. Can Vet J 2003, 44:907-913.

30. Morrill KM, Conrad E, Lago A, Campbell J, Quigley J, Tyler H: Nationwide evaluation of quality and composition of colostrum on dairy farms in the United States. J Dairy Sci 2012, 95:3997-4005.

31. NAHMS: Heifer Calf Health and Management Practices on U.S. Dairy Operations, 2007. In Edited by CEAH UAV. Fort Collins, CA; 2010.

32. Beam AL, Lombard JE, Kopral CA, Garber LP, Winter AL, Hicks JA, Schlater JL: Prevalence of failure of passive transfer of immunity in newborn heifer calves and associated management practices on US dairy operations. J Dairy Sci 2009, 92:3973-3980.

33. Stewart S, Godden S, Bey R, Rapnicki P, Fetrow J, Farnsworth R, Scanlon M, Arnold Y, Clow L, Mueller K, et al: Preventing bacterial contamination and proliferation during the harvest, storage, and feeding of fresh bovine colostrum. J Dairy Sci 2005, 88:2571-2578.

34. Greenland S, Drescher K: Maximum likelihood estimation of the attributable fraction from logistic models. Biometrics 1993, 49:865-872.

35. Cox DR: Regression models and life-tables. J R Stat Soc Series B 1972, 34:187-220

36. Cleves AC, Gould WW, Gutierrez RG: An introduction to survival analysis using stata. College Station, Texas: Stata Press; 2004.

\section{doi:10.1186/1746-6148-9-168}

Cite this article as: Aly et al: A randomized controlled trial on preweaning morbidity, growth and mortality in Holstein heifers fed a lacteal-derived colostrum replacer or pooled maternal colostrum. BMC Veterinary Research 2013 9:168. 